\title{
PERANCANGAN MESIN GERGAJI KAYU UNTUK PERAJIN PALLET KAYU
}

\author{
Akhmad Syarief $^{1)}$, Aditya Eko Kristanto ${ }^{2)}$ \\ ${ }^{1,2}$ Program Studi Teknik Mesin \\ Fakultas Teknik Universitas Lambung Mangkurat \\ JL. Akhmad Yani Km. 36 Banjarbaru, Kalimantan Selatan,70714 \\ e-mail: ekoekkooo@gmail.com
}

\begin{abstract}
Technology at all times continues to grow along with the progress of the times, not least in the furniture industry. In the development of timber techniques demands a quality product, it needs an effective and efficient process. This is also the underlying work of cutting timber. Initially the cutting of the wood was done manually by utilizing manpower and then changed using a whipsaw. The rapid development of technology makes hand saws rarely used and switches using sawing machines and saw tables. From the results of the design process of wood sawing machine summed up some things as follows: Dimensions of wood cutting machine $1500 \times$ $1000 \times 800 \mathrm{~mm}$, saws used in circular or cyrcle wood cutting machine with a circular motion saw blade, The rotation is passed from the motor to the saw blade is not in the fox and using the same pulleys of $74 \mathrm{~mm}$ diameter, wood cutting machine using $2 \mathrm{Hp}$ power, the level of safety on the wood cutting machine after theoretical calculations ranging from the transmission system, axis, and frame that is $9.524 \mathrm{~m} /$ sec belt speed is said to be good because $\leq 30 \mathrm{~m} / \mathrm{sec}$. The axle is said to be safe because the shear stresses that occur in the shaft are smaller than the allowable shear stress of $0,356 \mathrm{Kg} / \mathrm{mm}^{2}<2,46 \mathrm{Kg} / \mathrm{mm}^{2}$, and on the framework of the wood cutting machine the yield of the voltage is less than the yield strength material of 7,888 Mpa $\leq 207 \mathrm{MPa}$ with deflection 0,096 mm, In transmission belt $V$ used is $V$ type A42 belt, Image modification work of wood cutting machine used for machine making process contained in attachment.
\end{abstract}

Keywords: Saw, Pulley, Shaft

\section{PENDAHULUAN}

Gergaji merupakan peralatan utama dalam proses pemotongan kayu untuk dapat diolah lebih lanjut. Dalam proses pengerjaannya perajin membutuhkan waktu yang cukup lama dalam pengolahan kayu untuk dapat menjadi potongan yang lebih kecil. Mesin gergaji yang dimiliki perajin kayu rata-rata hanya mampu digunakan untuk memotong tanpa bisa dirubah ketinggian pisau gergaji sehingga proses yang lain kurang maksimal.

Pada saat ini sudah terdapat berbagai jenis mesin gergaji kayu dengan berbagai fungsinya. Mesin gergaji yang ada di kalangan perajin kayu sengon masih relatif sederhana sehingga fungsi dan penggunaanya belum bisa maksimal dikarnakan untuk membeli mesin gergaji kayu yang modern relatif mahal.

Mesin gergaji yang digunakan oleh perajin pallet kayu masih menggunakan mesin gergaji lingkaran tangan. Pada kondisi pekerja kurang maksimal dikarenakan pengerjaan pemotongan kayu yang harus lurus dan membutuhkan kepresisian yang tinggi sehingga menghasilkan produk yang berkualitas, dan tenaga yang di 
perlukan kepresisian hasil penggergajian kurang dapat maksimal sehingga dari segi penggunaan alat ini belum maksimal.

Persaingan di dunia industri tidak dapat terpisah dari mesin produksi. Mahalnya mesin produksi membuat para pengusaha kelas menengah kebawah menggunakan alat yang kurang mendukung kegiatan produksi. Perajin kayu adalah salah satu contoh dari kegiatan produksi. Meja gergaji kayu merupakan sebagian dari alat yang sering digunakan dalam pengerjaan pembuatan benda berbahan kayu.

\section{METODE PENELITIAN}

Metode yang digunakan pada penelitian ini adalah jenis metode perancangan berdasarkan:

1. Perhitungan konstruksi dan elemen mesin gergaji kayu dengan pertimbangan jenis material yang digunakan dan kecepatan putaran gergaji.

2. Hasil perencanaan terdiri dari data - data hasil perhitungan elemen mesin dan Gambar kerja tiap elemen mesin dan Gambar lengkap yang telah di-assembly.

\section{Diagram Alir Penelitian}

Diagram alir penelitian yang digunakan dalam penelitian ini ditunjukkan pada Gambar 1.
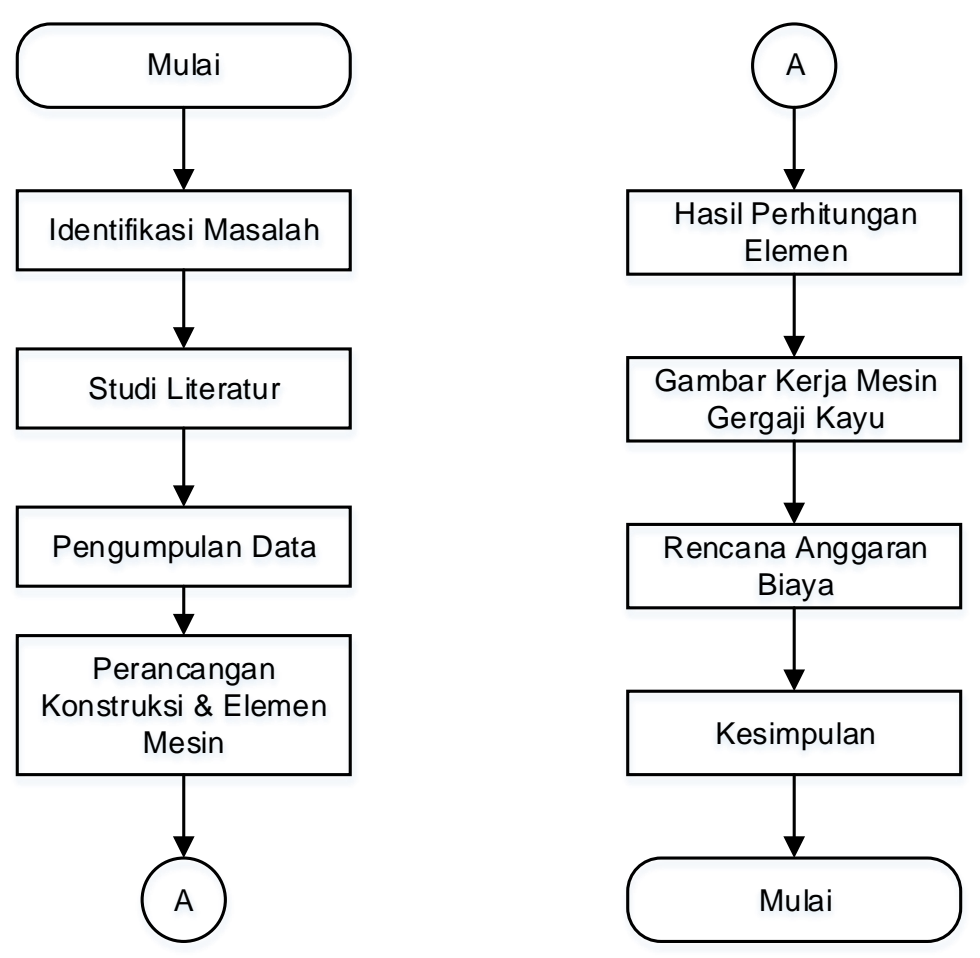

Gambar 1. Diagram Alir Penelitian 


\section{HASIL DAN PEMBAHASAN}

Model perancangan yang dilakukan penelitian ini ditunjukkan pada Gambar 2.

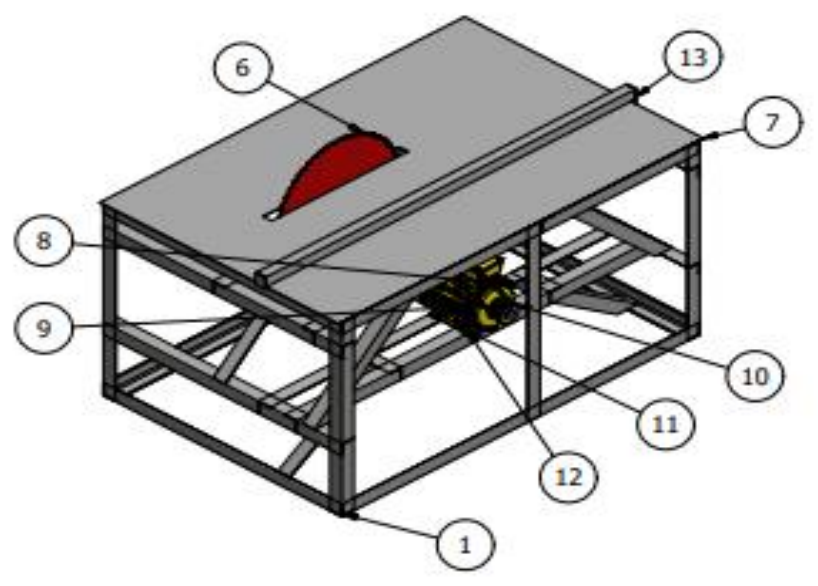

Gambar 2. Model Perencanaan Mesin Gergaji Kayu

Tabel 1. Keterangan model perencanaan mesin pemotong kayu

\begin{tabular}{|c|c|l|l|}
\hline ITEM & QTY & \multicolumn{1}{|c|}{ PART NUMBER } & DESCRIPTION \\
\hline 1 & 1 & Rangka & Equal-leg Angles \\
\hline 2 & 2 & Haouse Bearing & \\
\hline 3 & 1 & Poros & ST37 \\
\hline 4 & 1 & Pulley Gergaji & \\
\hline 5 & 2 & UCP205-16 & \\
\hline 6 & 1 & Gergaji Kayu & \\
\hline 7 & 1 & Alas & \\
\hline 8 & 1 & Motor & $2 \mathrm{Hp}$ \\
\hline 9 & 1 & Pulley Motor & \\
\hline 10 & 1 & V-Belt & Type A42 \\
\hline 11 & 8 & Bolt M8 $\times 35$ & Hexagon Head Bolts \\
\hline 12 & 8 & Nut M 8 & Hexagon Nuts \\
\hline 13 & 1 & Pembatas & \\
\hline
\end{tabular}

Menurut Telegraph dalam artikel mereka di bulan Febuari 2017, tinggi badan rata-rata dapat bervariasi berdasarkan kelompok ras dan etnis, yang dikelompokkan berdasarkan negara. Orang Indonesia memiliki tinggi badan rata-rata untuk laki-laki dewasa yaitu 5 kaki 1.83 inci $(159 \mathrm{~cm})$. Mesin gergaji ini didesain setinggi $800 \mathrm{~mm}$ agar nyaman digunakan ( tidak terlalu tinggi dan tidak terlalu rendah).

\section{Perancangan Poros Pisau}

Data yang diketahui dalam perancangan, yaitu:

- $\quad$ Putaran Poros : $2800 \mathrm{rpm}$

- Daya transmisi : $2 \mathrm{HP} \times 0,735=1,47 \mathrm{~kW}$

- $\quad$ Bahan Poros : St 37

- $\quad$ Tegangan Geser Kayu : 0,085 Kg/mm² (PKKI, 1961) 
1. Gaya pisau gergaji

$$
\sigma_{b}=\frac{F}{A}
$$

Dengan:

$$
\begin{array}{ll}
F & =\text { gaya gergaji }(\mathrm{Kg}) \\
A & =\text { luas penampang kayu } \\
\sigma_{b} & =\text { tegangan geser kayu }\left(\mathrm{Kg} / \mathrm{mm}^{2}\right)
\end{array}
$$

Sehingga luas penampang kayu, yaitu:

$$
\begin{aligned}
\mathrm{A} & =\frac{\alpha}{360^{\circ}} \cdot \pi \cdot r^{2} \cdot t \\
& =\frac{80}{360^{\circ}} \cdot 3,14 \cdot 254^{2} \cdot 2 \\
& =708,94 \mathrm{~mm}^{2} \\
\mathrm{~F} & =\sigma_{B} \cdot A \\
& =0,085 \mathrm{Kg} / \mathrm{mm} 2 \times 708,94 \mathrm{~mm}^{2} \\
& =60,2599 \mathrm{Kg}
\end{aligned}
$$

Sehingga gaya yang bekerja pada pisau gergaji, adalah :

$$
\begin{aligned}
\mathrm{F} & =\text { Berat } \times \text { gravitasi } \\
& =60,2599 \mathrm{Kg} \times 9,81 \\
& =590,54 \mathrm{~N}
\end{aligned}
$$

2. Faktor koreksi

Faktor koreksi yang di pakai adalah 1,2.

3. Daya rencana

$$
\begin{aligned}
P_{d} & =f_{c} . P(\mathrm{~kW}) \\
& =1,2 \times 1,47 \\
& =1,764(\mathrm{~kW})
\end{aligned}
$$

4. Momen puntir rencana

$$
\begin{aligned}
& T=9,74 \times 10^{5} \frac{P_{d}}{n_{1}} \\
& \mathrm{~T}=9,74 \times 10^{5} \frac{1,764}{2800} \\
& \mathrm{~T}=9,74 \times 10^{5} \times 0,00063 \\
& \mathrm{~T}=0,0061362 \times 100000 \\
& \mathrm{~T}=613,62 \mathrm{Kg} \cdot \mathrm{mm} \\
& \text { Jadi momen puntir yang terjadi sebesar } 613,62 \mathrm{Kg} . \mathrm{mm}
\end{aligned}
$$

5. Bahan poros yang di pakai adalah St 37

$$
\sigma_{b}=37 \mathrm{Kg} / \mathrm{mm}^{2}
$$

$\mathrm{Sf}_{1}$ (batas kelelahan punter) sebesar 6,0 untuk bahan $\mathrm{S}-\mathrm{C}$ dan $\mathrm{Sf}_{2}$ (pengaruh kekasaran permukaan) sebesar 2,5 
6. Tegangan geser yang diizinkan

$$
\begin{aligned}
& \tau_{a}=\frac{\sigma_{B}}{\left(S f_{1} \times S f_{2}\right)} \\
& \tau_{a}=2,46 \mathrm{Kg} / \mathrm{mm}^{2}
\end{aligned}
$$

7. $K_{t}=3$ (beban kejut atau tumbukan)

$C_{b}=2,3$ (faktor kemungkinan beban lentur)

8. Perhitungan diameter poros

$$
\begin{aligned}
& d_{s}=\left[\left(\frac{5,1}{T_{a}}\right) K_{t} \cdot C_{b} \cdot T\right]^{1 / 3} \\
& d_{s}=\left[\left(\frac{5,1}{2,46}\right) 3 \cdot 2,3 \cdot 613,62\right]^{1 / 3} \\
& d_{s}=20,627 \mathrm{~mm}
\end{aligned}
$$

Karena diameter poros mengikuti diameter dalam pada bentalan maka dibulatkan menjadi $25 \mathrm{~mm}$.

9. Tegangan geser

$$
\begin{aligned}
T & =\frac{T}{\left(\pi \cdot d_{S}^{3} / 16\right)} \\
\mathrm{T} & =\frac{5,1 \mathrm{~T}}{\mathrm{~d}_{\mathrm{S}}^{3}} \\
\mathrm{~T} & =\frac{5,1613,62}{20,627^{3}} \\
\mathrm{~T} & =0,356 \mathrm{Kg} / \mathrm{mm}^{2}
\end{aligned}
$$

10. $0,356 \mathrm{Kg} / \mathrm{mm}^{2}<2,46 \mathrm{Kg} / \mathrm{mm}^{2}$, sehingga poros pisau gergaji dengan diameter $25 \mathrm{~mm}$ aman untuk digunakan. 
SJME KINEMATIKA VOL.4 NO.2, 1 DESEMBER 2019, pp 1-14

Tabel 2. Ukuran Standar Pasak

\begin{tabular}{|c|c|c|c|c|c|c|c|c|c|c|c|}
\hline \multirow{2}{*}{$\begin{array}{c}\text { Uhuran } \\
\text { nominal } \\
\text { pasak } \\
b \times h\end{array}$} & \multirow{2}{*}{$\begin{array}{l}\text { Uharan } \\
\text { standar } \\
b_{1}, b_{\text {, }} \\
\operatorname{dan} b_{2}\end{array}$} & \multicolumn{2}{|c|}{ Ukuran standhr $h$} & \multirow[b]{2}{*}{$C$} & \multirow[b]{2}{*}{$t$} & \multirow{2}{*}{$\begin{array}{c}\text { Uharan } \\
\text { Standar } \\
l_{l}\end{array}$} & \multicolumn{3}{|c|}{ Ukuran S tandaar $l_{l}$} & \multirow{2}{*}{$\begin{array}{l}r_{1} \\
\text { dan } \\
r_{2}\end{array}$} & \multirow{2}{*}{$\begin{array}{l}\text { Referensi } \\
\text { Diameter poros } \\
\text { yang dapat } \\
\text { dipakai } d^{*+*}\end{array}$} \\
\hline & & $\begin{array}{l}\text { Pasak prismatis } \\
\text { Pasak luncur }\end{array}$ & $\begin{array}{c}\text { Pasak } \\
\text { Trus }\end{array}$ & & & & $\begin{array}{c}\text { Pasak } \\
\text { Prismat } \\
\text { i }\end{array}$ & $\begin{array}{l}\text { Pasak } \\
\text { Luncur }\end{array}$ & $\begin{array}{l}\text { Pasak } \\
\text { Tirus }\end{array}$ & & \\
\hline $\begin{array}{l}2 \times 2 \\
3 \times 3 \\
4 \times 4\end{array}$ & $\begin{array}{l}2 \\
3 \\
4\end{array}$ & \multirow{2}{*}{\multicolumn{2}{|c|}{$\begin{array}{l}2 \\
3 \\
4 \\
5 \\
6\end{array}$}} & $\begin{array}{l}0,16- \\
0,25\end{array}$ & $\begin{array}{l}6-20 \\
6-36 \\
8-45\end{array}$ & $\begin{array}{l}12 \\
18 \\
2,5\end{array}$ & \multirow{2}{*}{\multicolumn{2}{|c|}{$\begin{array}{l}1,0 \\
1,4 \\
1,8 \\
2,3 \\
2,8\end{array}$}} & $\begin{array}{l}0,5 \\
0,9 \\
1,2\end{array}$ & $\begin{array}{l}0.08- \\
0,16\end{array}$ & \multirow{2}{*}{$\begin{array}{rr}\text { Lebih dari } 6-8 \\
“ & 8-10 \\
“ & 10-12 \\
“ & 12-17 \\
“ & 17-22\end{array}$} \\
\hline $\begin{array}{l}5 \times 5 \\
6 \times 6\end{array}$ & $\begin{array}{l}5 \\
6\end{array}$ & & & \multirow{3}{*}{$\begin{array}{l}0,25- \\
0,40\end{array}$} & $\begin{array}{l}10.56 \\
14.70\end{array}$ & 3,0 & & & $\begin{array}{l}1,7 \\
2,2\end{array}$ & \multirow{3}{*}{$\begin{array}{l}0,16 \\
0,25\end{array}$} & \\
\hline$(7 \times 7)$ & 7 & 7 & 7,2 & & $16-80$ & 40 & 3,01 & 3,5 & 3,0 & & $20-25$ \\
\hline $8 \times 7$ & 8 & \multicolumn{2}{|l|}{7} & & 1890 & 40 & \multicolumn{2}{|c|}{3,3} & 2,4 & & $=\quad 22-30$ \\
\hline $\begin{array}{l}10 \times 8 \\
12 \times 8 \\
14 \times 9\end{array}$ & $\begin{array}{l}9 \\
10 \\
12\end{array}$ & \multicolumn{2}{|l|}{8} & \multirow{3}{*}{$\begin{array}{l}0,40- \\
0,60\end{array}$} & $\begin{array}{l}22.110 \\
28-140 \\
36-160\end{array}$ & $\begin{array}{l}5,0 \\
5,0 \\
5,5\end{array}$ & \multicolumn{2}{|c|}{$\begin{array}{l}3,3 \\
3,3\end{array}$} & $\begin{array}{l}2,4 \\
2,4 \\
2,9\end{array}$ & \multirow{3}{*}{$\begin{array}{l}0,25- \\
0,40\end{array}$} & $\begin{array}{l}. \\
* \quad 48-44 \\
\quad 440\end{array}$ \\
\hline$(15 \times 10)$ & 15 & 10 & 10,2 & & $40-180$ & $\frac{20}{10}$ & $50^{-1}$ & 15.5 & 5,0 & & \\
\hline $16 \times 10$ & 16 & \multicolumn{2}{|l|}{10} & & 45.180 & 6,0 & \multicolumn{2}{|c|}{4,3} & 3,4 & & $\begin{array}{ll}. & 50-58 \\
. & 58.65\end{array}$ \\
\hline $\begin{array}{l}18 \times 11 \\
20 \times 12 \\
22 \times 14\end{array}$ & $\begin{array}{l}18 \\
20 \\
22\end{array}$ & \multicolumn{2}{|l|}{$\begin{array}{l}11 \\
12 \\
14\end{array}$} & \multirow{3}{*}{$\begin{array}{l}0,60- \\
0,80\end{array}$} & $\begin{array}{l}50-200 \\
56-220 \\
63.250\end{array}$ & $\begin{array}{l}7,0 \\
7,5 \\
9,0\end{array}$ & \multicolumn{2}{|c|}{$\begin{array}{l}44 \\
49 \\
5,4\end{array}$} & $\begin{array}{l}3,4 \\
3,9 \\
4,4\end{array}$ & \multirow{3}{*}{$\begin{array}{l}0,40- \\
0,60\end{array}$} & $\begin{array}{ll}\approx & 65-75 \\
& 75-85\end{array}$ \\
\hline$(24 \times 16)$ & 24 & 16 & 16,2 & & 70.280 & 8,0 & 8,0 & 85 & 8,0 & & $80-90$ \\
\hline $\begin{array}{l}25 \times 14 \\
28 \times 16 \\
32 \times 18\end{array}$ & $\begin{array}{l}25 \\
28 \\
32\end{array}$ & \multicolumn{2}{|l|}{$\begin{array}{l}14 \\
16 \\
18\end{array}$} & & $\begin{array}{l}70-280 \\
80.320 \\
90.360\end{array}$ & $\begin{array}{l}90 \\
10,0 \\
11,0\end{array}$ & \multicolumn{2}{|c|}{$\begin{array}{l}5,4 \\
6,4 \\
7,4\end{array}$} & $\begin{array}{l}4,4 \\
5,4 \\
6,4\end{array}$ & & $\begin{array}{rr}* & 85-95 \\
* & 95-110 \\
* & 110-130\end{array}$ \\
\hline
\end{tabular}

Dengan diameter lebih dari 20-25 mm maka pasak yang umumnya digunakan adalah pasak dengan nomonal pasak $7 \times 7$. Jadi pasak yang digunakan dalam rancangan ini adalah pasak $7 \times 7$.

\section{Perencanaan Sabuk - V dan Puli}

Perhitungan perancangan sabuk - $V$ dan puli

Sabuk yang di pakai dalam perancangan transmisi ini adalah sabuk $V$ tipe $A$. Dari perancangan perhitungan poros diatas, selanjutnya dilakukan perhitungan sebagai berikut:

1. Penampang sabuk $V$ : Tipe $A$

$d_{\min }=65 \mathrm{~mm}$ (diameter minimum puli yang diizinkan)

2. $d_{p}=65 \mathrm{~mm}$

$D_{p}=d_{p} \times i=65 \times 1=65 \mathrm{~mm}$

$$
\begin{aligned}
d_{k} & =d_{\mathrm{p}}+2+4,5 \\
& =65+2+4,5 \\
& =74 \mathrm{~mm} \\
D_{k} & =D_{\mathrm{p}}+2+4,5 \\
& =65+2+4,5 \\
& =74 \mathrm{~mm}
\end{aligned}
$$

3. Kecepatan sabuk :

$$
\begin{aligned}
v & =\frac{\pi \cdot d_{p} \cdot n_{1}}{60 \times 1000} \\
v & =\frac{3,14 \times 65 \times 2800}{60 \times 1000}
\end{aligned}
$$




$$
\begin{array}{ll}
v & =\frac{571480}{60000} \\
v & =9,524 \mathrm{~m} / \mathrm{s}
\end{array}
$$

4. $(9,524 \mathrm{~m} / \mathrm{s}<30 \mathrm{~m} / \mathrm{s})$

5. Panjang keliling

$$
\begin{aligned}
& L=2 C+\frac{\pi}{2}\left(d_{p}+D_{p}\right)+\frac{1}{4 C}\left(D_{p}+d_{p}\right)^{2} \\
& L=2 \times 400+\frac{3,14}{2}(65+65)+\frac{1}{4 \times 400}(65+65)^{2} \\
& L=1067 \mathrm{~mm}
\end{aligned}
$$

6. Nomor nominal sabuk $V=42 \mathrm{inchi}, L=1067 \mathrm{~mm}$

7. Jarak sumbu poros

$b=2 L-\pi\left(D_{p}+d_{p}\right)$

$\mathrm{b}=2 \times 167-3,14(65+65)$

$\mathrm{b}=1725,8 \mathrm{~mm}$

$$
\begin{aligned}
& C=\frac{b+\sqrt{b^{2}-8\left(D_{p}-d_{p}\right)^{2}}}{8} \\
& C=\frac{1725,8+\sqrt{1725,8^{2}-8(65-65)^{2}}}{8}
\end{aligned}
$$

8. Sudut kontak

$$
\begin{aligned}
& \theta=180-\frac{57\left(D_{p}+d_{p}\right)}{C} \\
& \theta=180-\frac{57(65+65)}{304,45} \\
& \theta=180^{\circ} \\
& \mathrm{K}_{\theta}=1^{\circ} \text { (faktor koreksi) }
\end{aligned}
$$

\section{Perancangan Bantalan}

1. Gaya yang terjadi akibat putaran poros, yaitu:

$F=60,2599$ Kg $\times 9,8$

$F=590,54 N$

$F_{A}=0$ (beban aksial)

2. Putaran poros gergaji sebesar $2800 \mathrm{rpm}$.

$L_{h a}=20,000$ jam (umur bantalan yang di rencanakan) Bantalan 1 sama dengan bantalan 2, yaitu: $d=25 \mathrm{~mm}$ Nomor bantalan yang sementara di pilih adalah UCP205-16. Dengan kapasitas nominal dinamis spesifik $C=1100 \mathrm{Kg}$ dan kapasitas nominal statis spesifik $C_{o}=730$. 
3. Beban equivalen

Adapun perhitungan beban equivalen bantalan sebagai berikut :

Diketahui:

$F_{r}=60,2599 \mathrm{Kg}$

$F_{A}=0$

$x=0,56$

$v=1$

$y=1$

$K_{s}=2$

$P=\left(\right.$ x. v. $\left.\mathrm{F}_{\mathrm{r}}+\mathrm{y} . \mathrm{F}_{\mathrm{A}}\right) \mathrm{K}_{\mathrm{s}}$

$P=(0,56 \times 1 \times 60,2599+1 \times 0) 2$

$P=67,49 \mathrm{Kg}$

4. Umur nominal bantalan

$f_{n}=\left(\frac{33,3}{n}\right)^{1 / 3}$

$f_{n}=\left(\frac{33,3}{2800}\right)^{1 / 3}$

$f_{n}=0,228$

$f_{h}=f_{n} \frac{C}{P}$ (Faktor umur)

$f_{h}=2,228 \frac{1428,816}{67,49}$

$f_{h}=4,82$

$L_{h}=500 \mathrm{f}_{\mathrm{h}}^{3}$ (umur nominal)

$L_{h}=500 \times 4,82^{3}$

$L_{h}=55990.084 \mathrm{jam}$

$L_{h} \geq L_{h a}$

Jadi, bantalan yang di pakai nomor UCP205-16 aman di gunakan.

\section{Perencanaan Rangka}

Perencanaan rangka mesin gergaji kayu menggunakan analisis dari program software autodesk inventor 2018.

\begin{tabular}{|l|l|}
\multicolumn{1}{c|}{ Tabel 3. Physical } \\
\hline Mass & $90.004 \mathrm{~kg}$ \\
\hline Area & $57396.456 \mathrm{~mm}^{3}$ \\
\hline Volume & $11465.474 \mathrm{~mm}^{3}$ \\
\hline $\begin{array}{l}\text { Center of } \\
\text { Gravity }\end{array}$ & $\mathrm{x}=182.447 \mathrm{~mm}$ \\
& $\mathrm{y}=-173.842 \mathrm{~mm}$ \\
$\mathrm{z}=258.849 \mathrm{~mm}$
\end{tabular}

Berdasarkan Tabel 3 rangka meja gergaji ini memiliki massa $90,004 \mathrm{~kg}$, luas area $57396,456 \mathrm{~mm}^{2}$ serta volume sebesar $11465,474 \mathrm{~mm}^{3}$. 
SJME KINEMATIKA VOL.4 NO.2, 1 DESEMBER 2019, pp 1-14

Tabel 4. Material

\begin{tabular}{|c|c|c|}
\hline \multirow{2}{*}{$\begin{array}{l}\text { Name } \\
\text { General }\end{array}$} & \multicolumn{2}{|l|}{ Steel, Mild } \\
\hline & Mass Density & $7.850 \mathrm{~g} / \mathrm{cm}^{3}$ \\
\hline & Yield Strength & $207.000 \mathrm{MPa}$ \\
\hline & Ultimate Tensile Strength & $345.000 \mathrm{MPa}$ \\
\hline \multirow[t]{2}{*}{ Stress } & Young's Modulus & $220.000 \mathrm{GPa}$ \\
\hline & Poisson's Ratio & $0.275 \mathrm{ul}$ \\
\hline Part Name(s) & 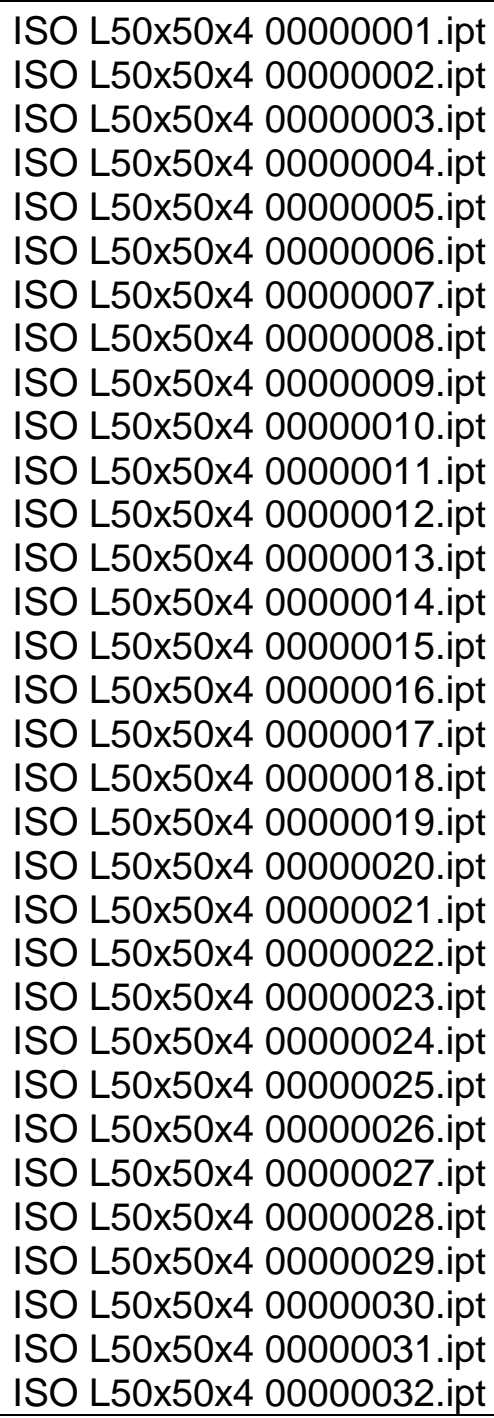 & \\
\hline
\end{tabular}

Tabel 4 menjelaskan material yang digunakan adalah baja ringan dengan massa jenis $7,850 \mathrm{~g} / \mathrm{mm}^{2}$, dengan kekuatan 207,000 Mpa dan kekuatan tekanan maksimum $345,000 \mathrm{Mpa}$. Material yang digunakan adalah besi profil L 50×50×4 mm sebanyak 32 bagian. 
Tabel 5. Gravitasi

\begin{tabular}{|l|l|}
\hline Load Type & Gravity \\
\hline Magnitude & $9810.000 \mathrm{~mm} / \mathrm{s}^{\wedge} 2$ \\
\hline Direction & $\mathrm{Y}$ - \\
\hline
\end{tabular}

Tabel 5 menjalaskan besar gaya gravitasi $9810,000 \mathrm{~mm} / \mathrm{s}^{2}$ dengan arah gravitasi pada sumbu Y-.

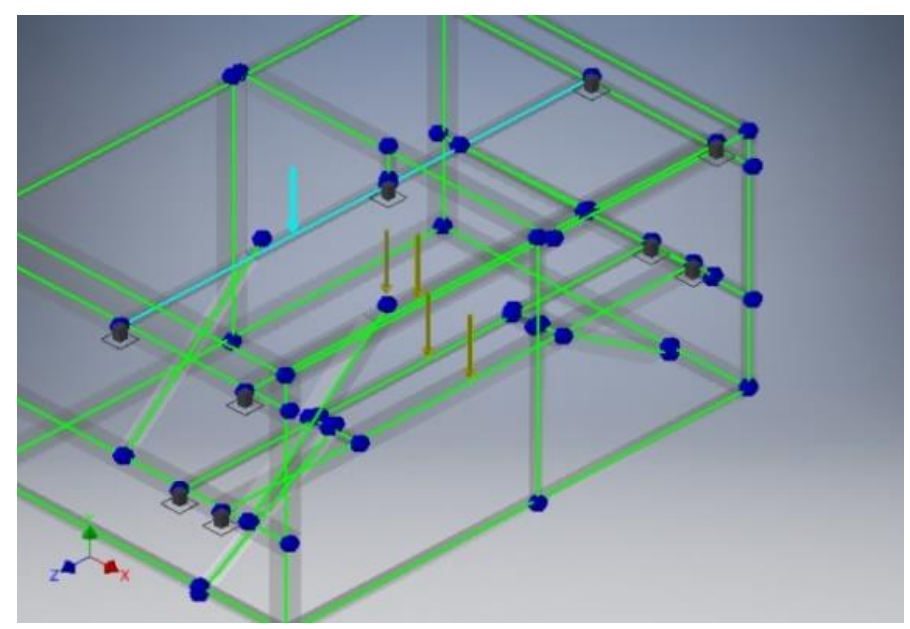

Gambar 3. Pembebanan 1

Tabel 6. Pembebanan 1

\begin{tabular}{|l|l|}
\hline Load Type & Force \\
\hline Magnitude & $50.000 \mathrm{~N}$ \\
\hline Beam Coordinate System & No \\
\hline Angle of Plane & $270.00 \mathrm{deg}$ \\
\hline Angle in Plane & $90.00 \mathrm{deg}$ \\
\hline FX & $0.000 \mathrm{~N}$ \\
\hline Fy & $-50.000 \mathrm{~N}$ \\
\hline Fz & $0.000 \mathrm{~N}$ \\
\hline Offset & $550.000 \mathrm{~mm}$ \\
\hline
\end{tabular}

Gambar 3 dan Tabel 6 menjelaskan bahwa tipe pembebanan adalah force sebesar 500,000 N serta gaya yang terjadi pada sumbu $\mathrm{Y}$ adalah $-500.000 \mathrm{~N}$. Pembebanan di tunjukkan oleh anak panah berwarna biru dan pada bagian rangka yang berwarna biru. 


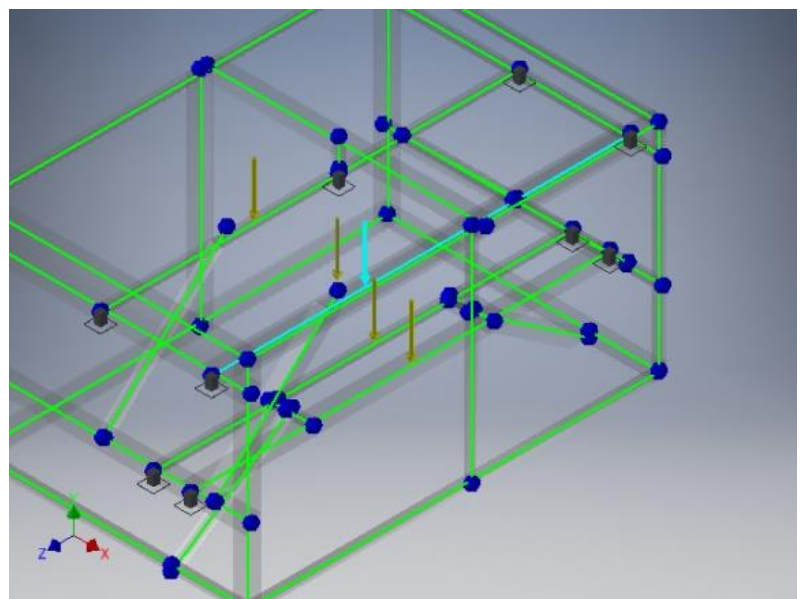

Gambar 4. Pembebanan 2

Tabel 7. Pembebanan 2

\begin{tabular}{|l|l|}
\hline Load Type & Force \\
\hline Magnitude & $50.000 \mathrm{~N}$ \\
\hline Beam Coordinate System & No \\
\hline Angle of Plane & $270.00 \mathrm{deg}$ \\
\hline Angle in Plane & $90.00 \mathrm{deg}$ \\
\hline Fx & $0.000 \mathrm{~N}$ \\
\hline Fy & $-50.000 \mathrm{~N}$ \\
\hline Fz & $0.000 \mathrm{~N}$ \\
\hline Offset & $550.000 \mathrm{~mm}$ \\
\hline
\end{tabular}

Gambar 4 dan Tabel 7 menjelaskan bahwa tipe pembebanan adalah force sebesar 500,000 N serta gaya yang terjadi pada sumbu $\mathrm{Y}$ adalah $-500.000 \mathrm{~N}$. Pembebanan di tunjukkan oleh anak panah berwarna biru dan pada bagian rangka yang berwarna biru.

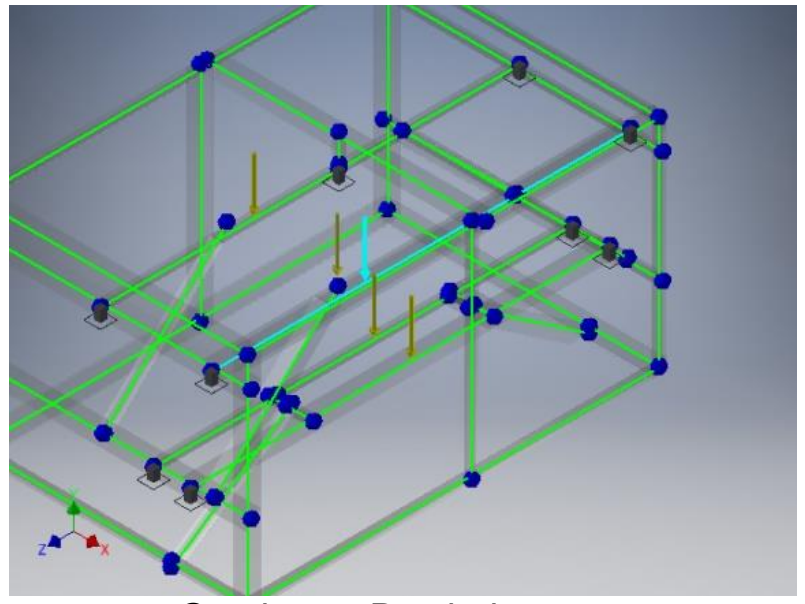

Gambar 5. Pembebanan 3 
Tabel 8. Pembebanan 3

\begin{tabular}{|l|l|}
\hline Load Type & Force \\
\hline Magnitude & $100.000 \mathrm{~N}$ \\
\hline Beam Coordinate System & No \\
\hline Angle of Plane & $270.00 \mathrm{deg}$ \\
\hline Angle in Plane & $90.00 \mathrm{deg}$ \\
\hline Fx & $0.000 \mathrm{~N}$ \\
\hline Fy & $-100.000 \mathrm{~N}$ \\
\hline Fz & $0.000 \mathrm{~N}$ \\
\hline Offset & $790.000 \mathrm{~mm}$ \\
\hline
\end{tabular}

Gambar 5 dan Tabel 8 menjelaskan bahwa tipe pembebanan adalah force sebesar $100,000 \mathrm{~N}$ serta gaya yang terjadi pada sumbu $\mathrm{Y}$ adalah $-100.000 \mathrm{~N}$. Pembebanan di tunjukkan oleh anak panah berwarna biru dan pada bagian rangka yang berwarna biru.

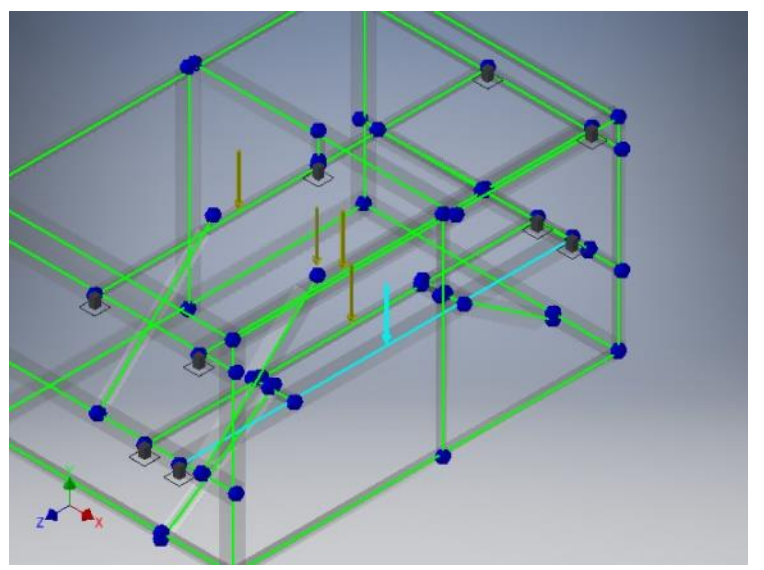

Gambar 6. Pembebanan 4

Tabel 9. Pembebanan 4

\begin{tabular}{|l|l|}
\hline Load Type & Force \\
\hline Magnitude & $100.000 \mathrm{~N}$ \\
\hline Beam Coordinate System & No \\
\hline Angle of Plane & $270.00 \mathrm{deg}$ \\
\hline Angle in Plane & $90.00 \mathrm{deg}$ \\
\hline Fx & $0.000 \mathrm{~N}$ \\
\hline Fy & $-100.000 \mathrm{~N}$ \\
\hline Fz & $0.000 \mathrm{~N}$ \\
\hline Offset & $790.000 \mathrm{~mm}$ \\
\hline
\end{tabular}

Gambar 6 dan Tabel 9 menjelaskan bahwa tipe pembebanan adalah force sebesar $100,000 \mathrm{~N}$ serta gaya yang terjadi pada sumbu $\mathrm{Y}$ adalah $-100.000 \mathrm{~N}$. Pembebanan di tunjukkan oleh anak panah berwarna biru dan pada bagian rangka yang berwarna biru. 
Tabel 10. Ringkasan hasil statis

\begin{tabular}{|c|c|c|c|}
\hline \multicolumn{2}{|l|}{ Name } & Minimum & Maximum \\
\hline \multicolumn{2}{|l|}{ Displacement } & $0.000 \mathrm{~mm}$ & $0.096 \mathrm{~mm}$ \\
\hline \multirow[t]{3}{*}{ Forces } & $F X$ & $-118.551 \mathrm{~N}$ & $134.069 \mathrm{~N}$ \\
\hline & Fy & $-173.003 \mathrm{~N}$ & $134.209 \mathrm{~N}$ \\
\hline & $F \boldsymbol{Z}$ & $-78.698 \mathrm{~N}$ & $108.660 \mathrm{~N}$ \\
\hline \multirow[t]{3}{*}{ Moments } & $M x$ & $-16590.151 \mathrm{~N} \mathrm{~mm}$ & $23427.089 \mathrm{~N} \mathrm{~mm}$ \\
\hline & My & $-22616.615 \mathrm{~N} \mathrm{~mm}$ & $19579.864 \mathrm{~N} \mathrm{~mm}$ \\
\hline & $M z$ & $-1119.443 \mathrm{~N} \mathrm{~mm}$ & $1205.192 \mathrm{~N} \mathrm{~mm}$ \\
\hline \multirow[t]{7}{*}{ Normal Stresses } & Smax & $-0.114 \mathrm{MPa}$ & 7.888 MPa \\
\hline & Smin & $-11.236 \mathrm{MPa}$ & $0.161 \mathrm{MPa}$ \\
\hline & $\operatorname{Smax}(M x)$ & $0.000 \mathrm{MPa}$ & $6.732 \mathrm{MPa}$ \\
\hline & $\operatorname{Smin}(M x)$ & $-9.506 \mathrm{MPa}$ & $-0.000 \mathrm{MPa}$ \\
\hline & $\operatorname{Smax}(M y)$ & $0.000 \mathrm{MPa}$ & $7.945 \mathrm{MPa}$ \\
\hline & $\operatorname{Smin}(M y)$ & $-9.177 \mathrm{MPa}$ & $-0.000 \mathrm{MPa}$ \\
\hline & Saxial & $-0.279 \mathrm{MPa}$ & $0.202 \mathrm{MPa}$ \\
\hline \multirow[t]{2}{*}{ Shear Stresses } & $T x$ & $-0.955 \mathrm{MPa}$ & $0.845 \mathrm{MPa}$ \\
\hline & Ty & $-0.956 \mathrm{MPa}$ & 1.233 MPa \\
\hline Torsional Stresses & $T$ & $-3.360 \mathrm{MPa}$ & $3.120 \mathrm{MPa}$ \\
\hline
\end{tabular}

Untuk mengetahui keamanan dari rangka mesin gergaji kayu hasil tegangan dibandingkan dengan yield stength material yaitu, 7,888 MPa $\leq 207 \mathrm{MPa}$. Jadi, rangka aman digunakan dengan hasil defleksi maksimal sebesar $0.096 \mathrm{~mm}$.

Dengan perkiraan biaya pembuatan 6.644 .000 rupiah meja gergaji ini jauh lebih murah di banding dengan meja gergaji yang sudah ada di pasaran yang harganya rata rata 15.000 .000 hingga 20.000 .000 dengan kapasitas motor sama, meja gergaji ini juga di rancang dengan ukuran lebih luas agar memungkinkan penggunanya dapat memotong atau mebelah kayu dengan ukuran yang lebih besar. Meja gergaji ini juga di rancang agar mudah di operasikan dan sederhana, dengan tujuan agar pengguna tidak kesulitan dalam pengoperasian meja gergaji ini.

\section{KESIMPULAN}

Dari data di atas maka dapet diambil kesimpulan sebagai berikut :

1. Hasil proses perancangan mesin gergaji kayu menyimpulkan beberapa hal sebagai berikut:

a. Dimensi mesin potong kayu $1500 \times 1000 \times 800 \mathrm{~mm}$

b. Gergaji yang digunakan pada mesin potong kayu berbentuk lingkaran atau cyrcle dengan gerakan mata gergaji berputar.

c. Putaran yang diteruskan dari motor kepada pisau gergaji tidak di rubah dan menggunakan pulley sama besar yaitu berdiameter $74 \mathrm{~mm}$.

d. Mesin potong kayu menggunakan daya sebesar $2 \mathrm{Hp}$. 
e. Tingkat keamanan pada mesin potong kayu setelah dilakukan perhitungan teoritis mulai dari 14ystem transmisi, poros, dan rangka yaitu kecepatan sabuk 9,524 $\mathrm{m} /$ detik dikatakan baik karena $\leq 30 \mathrm{~m} /$ detik. Poros di katakan aman karena tegangan geser yang terjadi pada poros lebih kecil dibanding tegangan geser yang diizinkan yaitu $0,356 \mathrm{Kg} / \mathrm{mm}^{2}<2,46 \mathrm{Kg} / \mathrm{mm}^{2}$, dan pada rangka mesin gergaji kayu hasil tegangan lebih kecil dari yield strength material sebesar 7,888 $\mathrm{MPa} \leq 207 \mathrm{MPa}$ dengan defleksi $0,096 \mathrm{~mm}$.

f. Pada transmisi sabuk V yang digunakan adalah sabuk V tipe A42.

g. Gambar kerja konstruksi mesin gergaji kayu digunakan untuk proses manufaktur pembuatan mesin terdapat dalam lampiran.

2. Hasil perhitungan perencanaan anggaraan biaya yang diperlukan untuk pembuatan mesin gergraji ini adalah 6.636.500 rupiah.

\section{DAFTAR PUSTAKA}

Admin. "Macam-Macam Mesin Bor" 11 november 2015. http://infoperkakas.com/macam-macam-mesin-bor/

Amin Suminto. "Mengoperasikan Mesin Ketam Perata (Surfacer / Perencana)" 30 april 2015.

http://www.vedcmalang.com/pppptkboemlg/index.php/departemen-bangunan30/982-as

Arif Suryo Wibowo. "Mesin Gergaji” mei 2014. http://ariefsuryowibowo.blogspot.co.id/2014/05/mesin-gergaji.html

Cahyo Widayanto, 2008. "Perancangan Mesin Gergaji Kayu Untuk Pengrajin Rak Buku" Skripsi Teknik Mesin, Universitas Negri Yogyakarta.

Diaurahman, 2018. "Proses Manufaktur Turbin Angin Sumbu Vertikal Tipe Darrieus" Sripsi Teknik Mesin, Universitas Lambung Mangkurat.

Doneh. "Mengenal Mesin Serut Kayu" 16 juli 2016. http://hobikayu.com/baca/mengenal-mesin-serut-kayu.html

Master Tukang. "mengena Imesin gergaji circular saw dan kegunaannya" 2 februari 2017. https://www.crafter.id/mengenal-mesin-gergaji-circular-saw-dan-kegunaanya/

Paul Gibson. "Kegunaan Mesin Profil Kayu” 17 desember 2015. http://infomebelterbaru.blogspot.co.id/2015/12/kegunaan-mesin-profilkayu.html

Robin Wu. "Indonesia, Negara dengan Penduduk Terpendek di Dunia" 11 juli 2017. https://www.idntimes.com/news/world/robin-wu/indonesia-negara-denganpenduduk-terpendek-c1c2/full

Sujiana G.N., 2016. "Proses Manufaktur Rak Benih Mesin Tanam Padi Tipe Pedal 2 Baris Model Tanam Jajar Legowo" Skripsi Teknik Mesin, Univesrsitas Lambung Mangkurat.

Solarso. 2004 " dasar perencanaan dan pemilihan elemen mesin" Pradnya paramita: Jakarta

Widarto, dkk., 2008. “ Teknik Pemesinan” Editor Budi Santoso, Direktorat Jenderal Manajemen Pendidikan Dasar dan Menengah Direktorat Pembinaan Sekolah Menengah Kejuruan Departemen Pendidikan Nasional Tahun 2008. 